\title{
Evolution of the deformation profile of a horizontal thin ethanol layer when heated locally
}

\author{
Serafim Spesivtsev ${ }^{1,2, *}$, and Yuriy Lyulin ${ }^{1,3}$ \\ ${ }^{1}$ Institute of Thermophysics, 630090, Novosibirsk, Russia \\ ${ }^{2}$ Novosibirsk State University, 630090, Novosibirsk, Russia \\ ${ }^{3}$ Tomsk Polytechnic University, 634050, Tomsk, Russia
}

\begin{abstract}
Thermocapillary breakdown of thin horizontal layer of ethanol when heated from a localized heat source was studied experimentally. The influence of layer depth on the breakdown process was investigated. Evolution of the layer thickness in the heating point and deformation profile were being monitored and the critical thickness of the layer was evaluated using confocal technique. Pulsations of layer thickness over the heating area before the breakdown have been found.
\end{abstract}

\section{Introduction}

Study of heat elimination from a pointed heat source becomes one of the most significant problems in thermal physics because of its straight association with the cooling of microelectronics [1]. Permanent development of microelectronic equipment leads to complication of the microchip structure and formation of nonuniform heat flux distribution on the chip surface. Heat flux in some small zones is much greater than the chip regular [2], of the order of $1 \mathrm{~kW} / \mathrm{cm}^{2}$. This effect could significantly deteriorate reliability and performance of the device.

Nowadays, there are a number of successful methods for cooling of local hot spots, for example spray cooling, thermoelectric coolers, boiling in microchannels. One of the most effective techniques for eliminating such high heat fluxes from a local heat source is technology based on processes with phase change such as evaporation of a thin liquid layer [3]. In this case the main mechanism of heat transfer from the heat source is an intensive evaporation due to latent heat of vaporization. Dynamics of evaporation and, therefore, the heat elimination from the heat source significantly depend on the conditions in a layer [4]. Especially, the breakdown of liquid layer leads to powerful decreasing of heat transfer from a localized hot spot [5]. Processes of liquid layer breakdown are actively investigated experimentally [5-7] and theoretically [8-10].

The aim of the present work is to study the breakdown dynamics and measure the deformation profile of an evaporating horizontal liquid layer when heated locally.

\footnotetext{
* Corresponding author: simafir94@gmail.com
} 


\section{Experimental facility}

Experiments were carried out on the setup shown in Fig. 1. The working fluid is supplied to the test cell with the assistance of the syringe pump and a horizontal liquid layer is created. The thickness of liquid layer is varied from 300 to $700 \mu \mathrm{m}$. The layer of liquid is opened to the atmosphere and maintained on the surface of the working area using sharp edge on the substrate perimeter. Spot heating of the horizontal liquid layer takes place in the center of the substrate. The test cell consists of caprolon base, metallic substrate and the heating element. The caprolon base has a special cut on the upper side for installation of the substrate and a central through hole with a diameter of $1.6 \mathrm{~mm}$. The substrate is made of stainless steel and has a diameter of $50 \mathrm{~mm}$ and a thickness of $1 \mathrm{~mm}$. In the center of the substrate is a closed hole with a diameter of $1.6 \mathrm{~mm}$ and a height of $0.8 \mathrm{~mm}$. The heating element is made of brass and has a round tip with a diameter of $1.6 \mathrm{~mm}$ and a height of 3 $\mathrm{mm}$. It is tightly inserted into the closed hole of the substrate through the caprolon base. Thermal paste is used for better thermal contact between the heater tip and the substrate. The distance between the tip and the upper side of substrate is $0.2 \mathrm{~mm}$. The power of heating element is controlled by the power supply. Insulating material is located on the underside of the heater to minimize heat losses. Temperature in the test cell is measured by thermocouples (type $\mathrm{K}$ ) connected to the measuring system with an accuracy of $0.1^{\circ} \mathrm{C}$. Location of the thermocouples is shown in Fig. 1. Relative humidity and atmosphere temperature are measured using the thermohygrometer Testo 645 with an accuracy of $2 \%$ and $0.1{ }^{\circ} \mathrm{C}$, respectively.

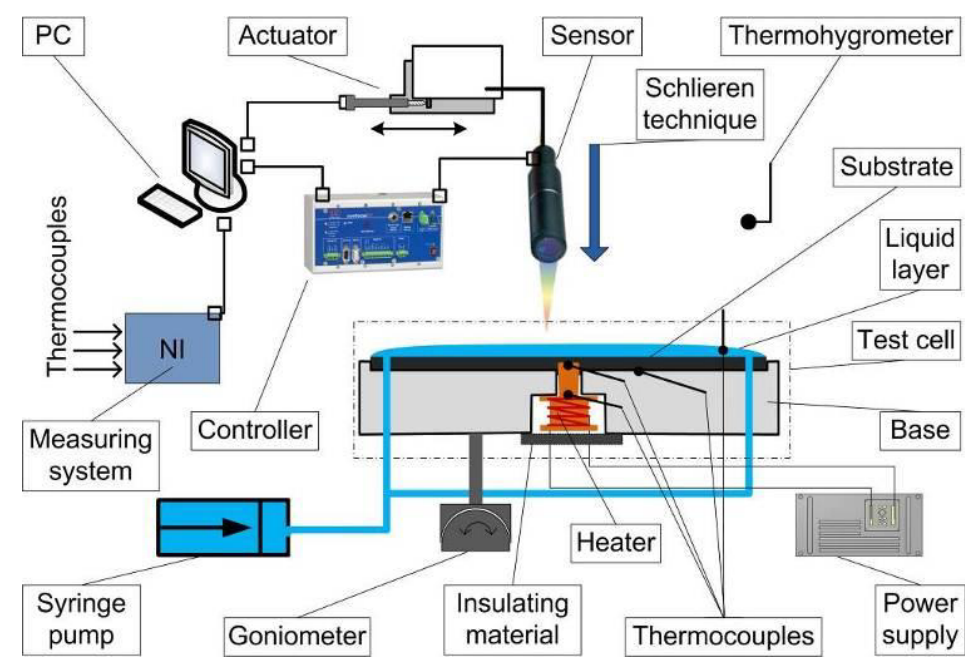

Fig. 1. Scheme of the experimental setup.

The heat flux density is determined by measuring the temperature difference between two different sections along the heater tip. The height of the horizontal liquid layer is maintained in constant position during the all experiment. Confocal system Micro-epsilon is used for measuring the layer thickness over the heating element. The system consists of the controller and the sensor. Sensors have the spatial resolution from 10 to $60 \mathrm{~nm}$, the accuracy $0.35-0.7 \mu \mathrm{m}$, the spot diameter $6-16 \mu \mathrm{m}$ and the measuring range $0.3-10 \mathrm{~mm}$. The maximum temporal resolution is $100 \mu \mathrm{s}$. The sensor is fixed on the three-dimensional positioning system with high-speed linear actuator on one of the horizontal axes. Linear actuator is controlled from personal computer and by special software. The maximum speed the axis moves at is $104 \mathrm{~mm} / \mathrm{s}$. The sensor moves in range of $50 \mathrm{~mm}$ by steps of $1 \mu \mathrm{m}$. Also it moves in two other axes with the help of two hand-operated linear stages in range of 50 
$\mathrm{mm}$. For visualizing the deformation of the surface and recording the layer breakdown dynamics schlieren technique with Photron FASTCAM 675K-M3 high-speed camera was used (at $5000 \mathrm{fps}, 640 \times 640$ pixels, $25 \mu \mathrm{m} /$ pix). The test cell was installed in a horizontal position with the help of two-axis goniometer. Equilibrium contact angle of the substrate surface is defined by Young-Laplace equation [11] at room temperature of $25 \pm 2{ }^{\circ} \mathrm{C}$ and is equal to $\theta=8 \pm 1^{\circ}$. Profilometer "Micro Measure 3D station" was used for measuring the roughness of substrates. Average value of the substrate roughness is equal to $R_{a}=0.037$ $\mu \mathrm{m}$.

\section{Experimental results and discussion}

Experiments were conducted at atmospheric pressure, temperature and relative humidity of $28 \pm 2{ }^{\circ} \mathrm{C}$ and $25 \pm 3 \%$, respectively. Layer thickness was ranged from 300 to $700 \mu \mathrm{m}$. Ethanol $(95 \%)$ was used as a working fluid. Heater temperature range was $20-105^{\circ} \mathrm{C}$. The temperature values were measured at the moment of layer breakdown. Heat flux density was varied from 0 to $95.3 \mathrm{~W} / \mathrm{cm}^{2}$. Injection liquid flow rate was up to $200 \mu \mathrm{l} / \mathrm{min}$. During the experiment heat flux is increased up to a critical value at which the liquid layer ruptures. At this moment heating process is stopped to prevent the failure of heating element.

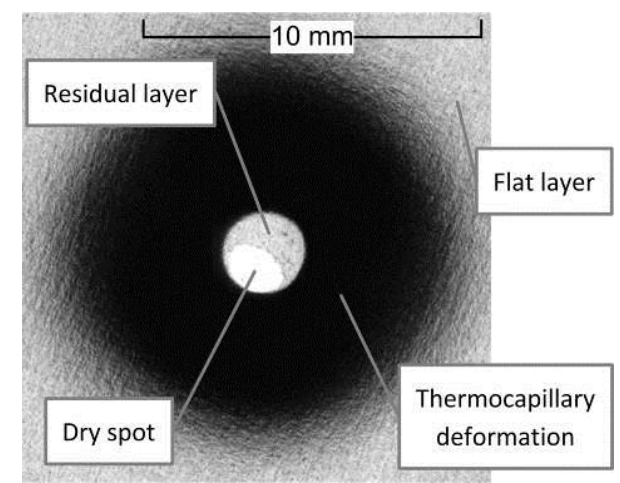

Fig. 2. Visualization of breakdown dynamics and formation of the dry spots.

It was found that breakdown process consists of several steps. At the beginning, thinning of the liquid layer over the heating area due to the effect of thermocapillary forces $[12,13]$ and evaporation is observed. Further thinning leads to the formation of residual liquid layer in the area of the local heating. Then the residual layer evaporates until its thickness reaches the critical and breakdown of the liquid layer occurs, Fig. 2 [5, 6]. After the breakdown the whole area of the local heating rapidly dries and quite symmetrical circular dry spot is formed.

Evolution of the layer thickness in the center of substrate is observed with the help of the confocal system. All detected steps of the breakdown process observed by the schlieren technique were also confirmed using the confocal method. Dependence of the layer thickness over the heating area on time is shown in Fig. 3. 


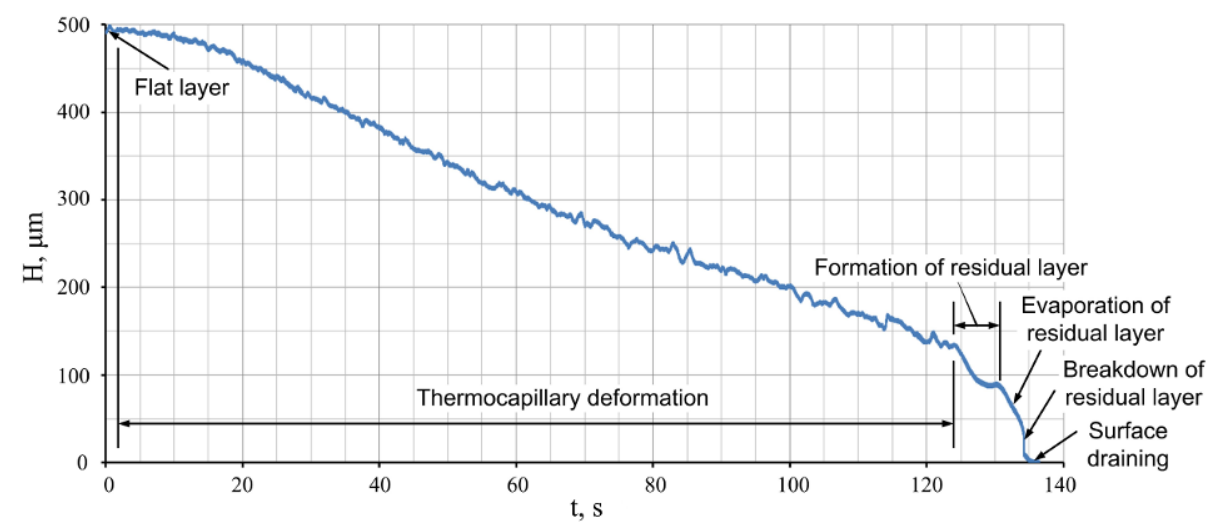

Fig. 3. Dependence of the layer thickness over the heating area on time (initial layer depth $500 \mu \mathrm{m}$ ).

Evolution of the layer thickness before the breakdown was measured for different initial layer depth in range from 300 to $700 \mu \mathrm{m}$ (Fig. 4). Critical thickness of residual is less than $30 \mu \mathrm{m}$. It is assumed that critical thickness of the residual layer for present substrate mostly depends on the properties of working liquid. The time of dry spot formation is decreased when the layer thickness and, accordingly, the local heating intensity is increased. The time varies from 6 to 0.67 seconds. Temperature in the center of substrate increases and more intense evaporation of residual layer takes place. The main mechanism of the outflow of the liquid from the heating zone before the residual layer formation is the thermocapillary shear stress, and after it this is the evaporation. At small liquid thickness the viscosity suppresses thermocapillary flows.

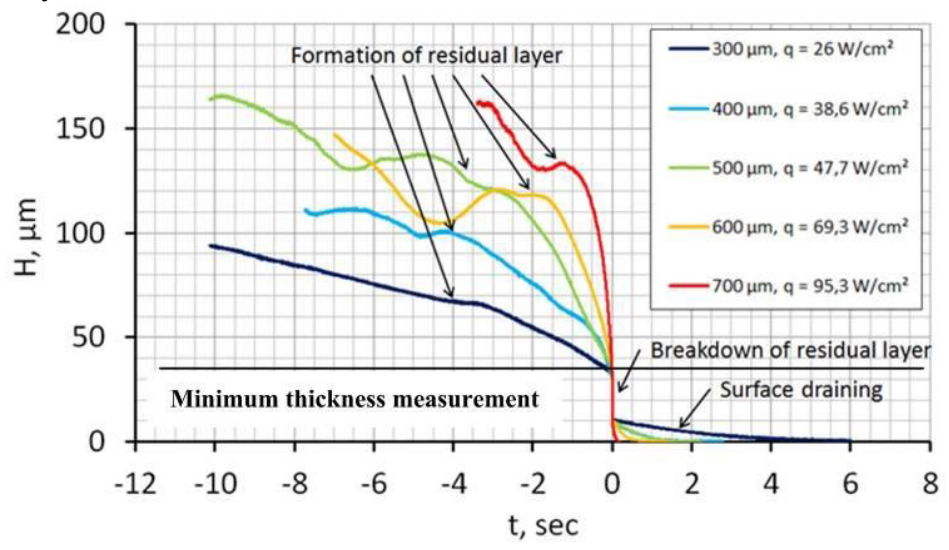

Fig. 4. Dependence of the layer thickness over the heating area on time for different initial layer depth.

Evolution of the layer deformation profile is shown in Fig. 5. Pulsations of the layer thickness before formation of the residual layer have been observed. The presence of the thickness pulsations is presumably connected with convective instability, caused by the intense heat and mass transfer in the heating area. 


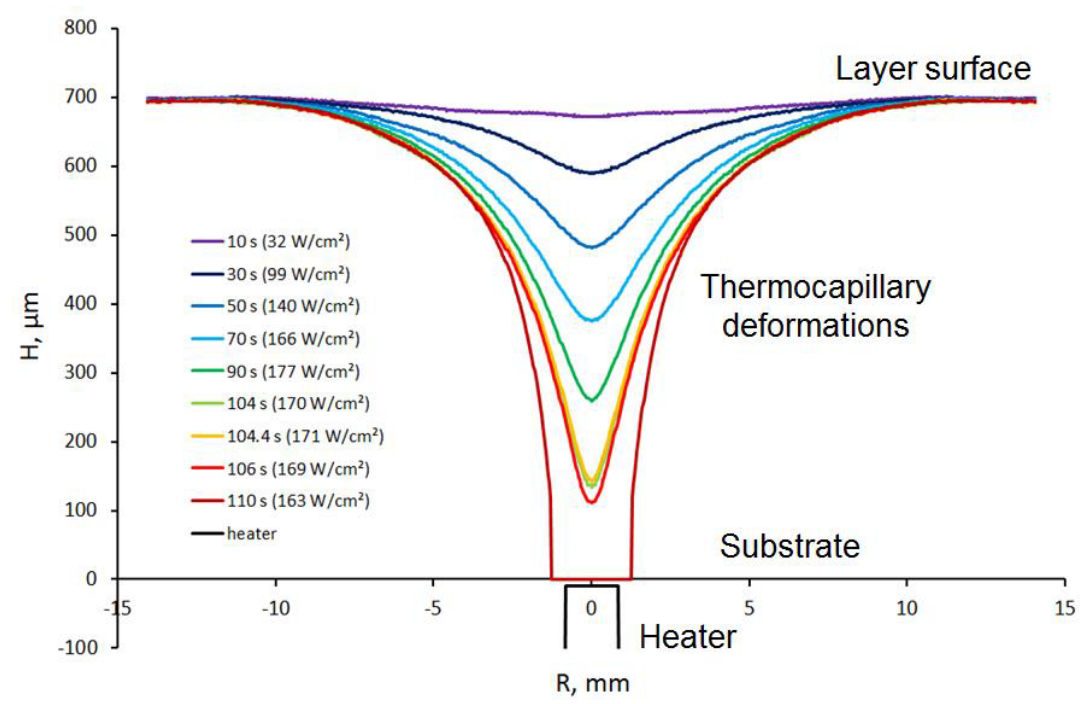

Fig. 5. Measurements of the layer surface profile in case of local heating.

\section{Conclusion}

Influence of the layer depth on the breakdown dynamics of liquid layer was studied. Evolution of the layer thickness in the heating point and deformation profile were being monitored using confocal technique. The existence of residual liquid layer over the heating area before the breakdown has been proved. It is found the critical thickness of residual layer is less than $30 \mu \mathrm{m}$. Pulsations of layer thickness over the heating area before the formation of residual layer have been observed. The main drainage mechanism for the residual layer is evaporation.

The study was financially supported by the Russian Science Foundation (Project 14-1901755).

\section{References}

1. A. Bar-Cohen, P. Wang, J. Heat Transf. 134, 051017 (2012)

2. R. Mahajan, C. Chiu, G. Chrysler, Proceedings of the IEEE 94, 1476 (2006)

3. E.Ya. Gatapova, O.A. Kabov, I.V. Marchuk, Tech. Phys Lett 30, 418 (2004)

4. A.A. Fedorets, I.V. Marchuk, O.A. Kabov, Interfacial Phenomena and Heat Transfer 1, $1(2013)$

5. Yu.V. Lyulin, S.E. Spesivtsev, I.V. Marchuk, O.A. Kabov, Techn. Phys. Lett 41, 1034 (2015)

6. D.V. Zaitsev, D.A. Rodionov, O.A. Kabov, Microgravity Sci. Tec. 19,100 (2007)

7. D.V. Zaitsev, O.A. Kabov, Microgravity Sci. Tec 35, 825 (2011)

8. V. S. Ajaev, Interfacial Phenomena and Heat Transfer 1, 1 (2013)

9. M. B. Williams and S. H. Davis, J. Colloid Interf. Sci. 90, 220 (1982)

10. J. P. Burelbach, S. G. Bankoff and S. H. Davis, Phys. Fluid A Fluid Dyn. 2, 313 (1990)

11. I.V. Marchuk, V.V. Cheverda, P.A. Strizhak, and O.A. Kabov, Thermophys. Aeromech+ 22, 297 (2015)

12. I. V. Marchuk, J. Eng Thermophys 18, 227 (2009)

13. I.V. Marchuk, J. Eng Thermophys 24 (2015) 